14

\title{
Нековалентные взаимодействия подскорлуповой яичной мембраны
}

\author{
() В.И. Иванов-Омский, С.Г. Ястребов \\ Физико-технический институт им. А.Ф. Иофффе РАН, Санкт-Петербург, Россия \\ ๑ E-mail: yastrebov@mail.ioffe.ru
}

Поступило в Редакцию 10 марта 2020 г.

В окончательной редакции 9 июня 2020г.

Принято к публикации 9 июня 2020 г.

\begin{abstract}
Изучен спектр активных в инфракрасной области нековалентных взаимодействий для мембраны оболочки куриного яйца. Оценены энергии этих взаимодействий. Выполнено сравнение результатов с данными, ранее полученными для различных образцов аортального клапана человека. Делается вывод о перспективности применения подскорлуповой яичной мембраны в качестве аналога базального слоя аортального клапана, пригодного для проведения биофизических экспериментов in vitro.
\end{abstract}

Ключевые слова: кальциноз аортального клапана, водородная связь, ИК-спектроскопия.

DOI: 10.21883/PJTF.2020.18.49993.18282

Кальциноз аорты и ее клапанов представляет собой большую проблему, поскольку в конечном счете приводит либо к инвалидизации, либо к гибели пациента. Заметим, что в процессе развития кальциноза в ткани аорты образуются значительные по размеру области отложений кальцинатов, т. е. гидроксиапатита [1]. Однако до последнего времени оставался невыясненным вопрос о том, почему при значительных размерах областей кальцинации данные рентгенофазового анализа соответствуют наноразмерным кластерам гидроксиапатита. Объяснение этого феномена дано нами в работе [2], где было показано, что нанокластеры гидроксиапатита формируются в наноразмерных порах базальной мембраны аорты и ее клапанов. Однако следует констатировать, что детальное исследование зарождения и последующего роста кластеров в базальной мембране in vivo затруднено ввиду большого числа технических и этических трудностей, связанных со спецификой получения информации о росте нанокластеров в ткани аорты. Поэтому с целью изучения возможности замедления данного процесса или даже обращения его во времени необходимо иметь возможность проводить опыты в лабораторных условиях in vitro. В связи с этим встает вопрос об удобной биологической модели, которую возможно использовать при постановке опытов по выращиванию нанокластеров in vitro. В связи с этим обращает на себя внимание работа [3], в которой впервые in vitro проведен синтез нанокластеров гидроксиапатита в нанопоровом пространстве подскорлуповой яичной мембраны. Оказалось возможным вырастить вытянутые нанокластеры с продольными размерами до $30 \mathrm{~nm} \mathrm{и}$ поперечными размерами до $5 \mathrm{~nm}$. По-видимому, нанокластеры, заполнив пору, достигают ее границ, которые препятствуют дальнейшему росту. Нанокластеры могут фиксироваться водородными связями на поверхности поры. Поэтому интересно исследовать энергии водородных связей в мембране куриного яйца. Энергия водородной связи характеризует энергию молекулярного взаимодействия в мембране. Для ее оценки применим метод ИК-спектроскопии. Для анализа из спектра, приведенного в работе [4], выделим полосу поглощения гидроксильными (-OH) группами (см. рисунок). Именно содержащиеся в них протоны ответственны за формирование водородных связей (Н-связей). Влияние образования Н-связей на колебательные частоты ОН-групп довольно хорошо изучено [5], что может быть использовано для оценки величин энергий их связей. Цель настоящей работы состоит в оценке энергии Н-связи в мембране куриного яйца для сравнения с аналогичной энергией для аортального клапана человека. Сравнение этих двух величин позволит сделать вывод о перспективности использования подскорлуповой мембраны куриного яйца в качестве модели базальной мембраны аортального клапана человека. Эта цель достигается разбиением ИК-спектра из работы [4] в области колебаний растяжения водородной связи на гауссианы и сравнением па-

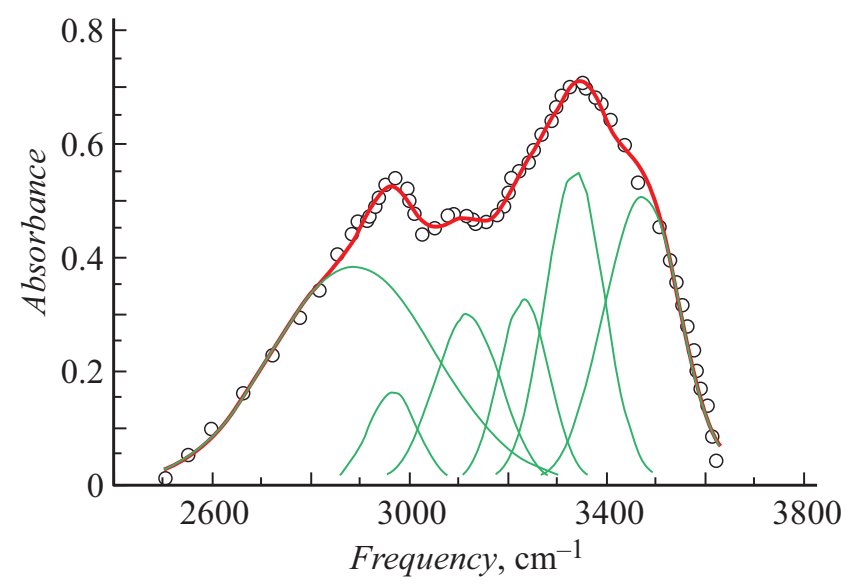

Спектр полосы Амид А подскорлуповой пленки. Точки - эксперимент, тонкие линии - гауссовы контуры деконволюции, жирная линия - огибающая контуров деконволюции. 
Результаты оценок энергий Н-связей в подскорлуповой пленке яйца

\begin{tabular}{c|c|c}
\hline Частоты ОН-групп, $\mathrm{cm}^{-1}$ & Сдвиг частоты ОН-групп, \\
$\mathrm{cm}^{-1}$ & 421 & $\begin{array}{c}\text { Энергия Н-связи, } \\
\mathrm{kJ} / \mathrm{mol}\end{array}$ \\
\hline 3229 & 227 & 22.9 \\
3423 & 121 & 15.8 \\
3529 & 7.1
\end{tabular}

раметров разложения с эталонной оценкой, приведенной B [5].

Оценим величину энергии Н-связи в мембране яйца. На рисунке представлен фрагмент спектра ИК-поглощения яичной оболочки, содержащий полосу Амид А, вместе с результатом его деконволюции гауссовыми контурами методом наименьших квадратов [6]. Отметим, что оказалось достаточно шести контуров, чтобы среднеквадратичное отклонение не превышало 0.992. Результат этой процедуры представлен на рисунке кривыми гауссовых контуров и кривой их огибающей. Контуры с максимумами при 2850 и $2964 \mathrm{~cm}^{-1}$ соответствуют хорошо известным полосам поглощения метил-метиленовыми группами, которые, как известно, индифферентны по отношению к формированию Н-связей и по этой причине оказываются вне рамок нашего интереса, хотя и могут служить реперами, подтверждающими надежность использованной градуировки частот. Полоса вблизи $3100 \mathrm{~cm}^{-1}$ может быть отнесена к поглощению валентными колебаниями аминокислотных $\mathrm{NH}_{2}$-групп, которые хотя и охватываются Н-связями, но по причине отсутствия надежных данных по их влиянию на собственную частоту колебаний этой группы также остаются вне рамок нашего анализа. А полоса при $3231 \mathrm{~cm}^{-1}$ может быть отнесена к поглощению ОН-группой, охваченной Н-связью. Именно параметры этого контура будут использованы в дальнейшем для оценки величины энергии Н-связи. Контур при $3333 \mathrm{~cm}^{-1}$ является типичным для валентных колебаний $\mathrm{NH}$-группы коллагена $[7,8]$, что может дополнительно подтвердить нашу идентификацию спектра, равно как и контур при $3470 \mathrm{~cm}^{-1}$ (деформационные колебания ОН-групп) [8]. Воспользуемся теперь полученными нами величинами частот колебаний ОН-групп для оценки энергий охваченных ими Н-связей по величине сдвига этих частот от частоты деформационных колебаний свободных от Н-связей групп ОН $\left(3650 \mathrm{~cm}^{-1}\right.$ [5]) с помощью эмпирического корреляционного соотношения величин сдвига и энергий [5]. Полученные таким образом результаты представлены в таблице. Видно, что в пленке энергия Н-связи близка по величине к ее типичному значению в аортальном клапане здорового человека $(22.9 \mathrm{~kJ} / \mathrm{mol})$, но несколько меньше, чем в костной ткани $(24.9 \mathrm{~kJ} / \mathrm{mol})$ [9].

На основе указанного выше можно сделать вывод, что близость энергий нековалентных взаимодействий подскорлуповой мембраны куриного яйца к аналогичным параметрам базальной мембраны аортального клапана также свидетельствует о том, что она является хорошим аналогом для проведения биофизических экспериментов in vitro.

\section{Конфликт интересов}

Авторы заявляют, что у них нет конфликта интересов.

\section{Список литературы}

[1] Izquierdo-Gómez M.M., Hernández-Betancor I., García-Niebla J., Marí-López B., Laynez-Cerdeña I., Lacalzada-Almeida H.I. // Biomed. Res. Int. 2017. V. 2017. P. 5178631 (1-12).

[2] Ястребов С.Г., Гуляев Н.И., Галенко А.С., Прус М., Сиклицкая А.В. // Письма в ЖТФ. 2019. Т. 45. В. 4. С. 46-49.

[3] Neelakandeswari N., Sangami G., Dharmaraj N. // Synth. React. Inorg. Met.-Org. Nano-Met. Chem. 2011. V. 41. N 5. P. 513-516.

[4] Torres-Mansilla A.C., Delgado-Mejia E. // Int. J. Poult. Sci. 2017. V. 16. N 11. P. 451-456.

[5] Иванов-Омский В.И. // Письма в ЖТФ. 2014. Т. 40. В. 16. C. $28-35$.

[6] Marquardt D.W. // J. Soc. Industr. Appl. Math. 1963. V. 11. N 2. P. 431-441.

[7] Kudo S., Ogawa H., Yamakita E., Watanabe Sh., Suzuki T., Nakashima S. // Appl. Spectr. 2017. V. 71. N 7. P. 1621-1632.

[8] Movasaghi Z., Rehman S., Rehman Ih. // Appl. Spectr. Rev. 2008. V. 43. N 2. P. 134-179.

[9] Иванов-Омский В.И., Рутковский К.С., Гуляев Н.И., Галенко А.С., Ястребов С.Г. // Письма в ЖТФ. 2019. Т. 45. B. 18 . C. $28-35$. 